\title{
Cryogenic Refractive Index of Heraeus Homosil Glass
}

\author{
${ }^{a}$ Kevin H. Miller, ${ }^{\mathrm{a}}$ Manuel A. Quijada, ${ }^{\mathrm{b}}$ Douglas B. Leviton \\ ${ }^{a}$ Goddard Space Flight Center, 8800 Greenbelt Road, Greenbelt, MD 20771 \\ ${ }^{\mathrm{b}}$ Leviton Metrology Solutions, Inc., Boulder, CO 80301
}

\begin{abstract}
This paper reports measurements of the refractive index of Homosil (Heraeus) over the wavelength range of $0.34-3.16$ $\mu \mathrm{m}$ and temperature range of $120-335 \mathrm{~K}$. These measurements were performed by using the Cryogenic High Accuracy Refraction Measuring System (CHARMS) facility at the NASA's Goddard Space Flight Center. These measurements were in support of an integrated Structural-Thermal-Optical-Performance (STOP) model that was developed for a fieldwidened Michelson interferometer that is being built and tested for the High Spectral Resolution Lidar (HSRL) project at the NASA Langley Research Center (LaRC). The cryogenic refractive index measurements were required in order to account for the highly sensitive performance of the HSRL instrument to changes in refractive index with temperature, temperature gradients, thermal expansion, and deformation due to mounting stresses. A dense coverage of the absolute refractive index over the aforementioned wavelength and temperature ranges was used to determine the thermo-optic coefficient $(\mathrm{dn} / \mathrm{dT})$ and dispersion relation $(\mathrm{dn} / \mathrm{d} \lambda)$ as a function of wavelength and temperature. Our measurements of Homosil will be compared with measurements of other glasses from the fused silica family studied in CHARMS as well as measurements reported elsewhere in the literature.
\end{abstract}

Keywords: Homosil, Heraeus, fused silica, High Spectral Resolution Lidar, CHARMS, cryogenic refractive index

\section{INTRODUCTION}

The Cryogenic High Accuracy Refraction Measuring System (CHARMS) was developed at Goddard Space Flight Center (GSFC), primarily in support of the James Webb Space Telescope (JWST), to measure cryogenic refractive indices (at temperatures as low as $15 \mathrm{~K}$ ) with unparalleled accuracy using minimum deviation refractometry. ${ }^{1,2}$ In this report Heraeus Homosil was measured in support of the High Spectral Resolution Lidar (HSRL) project at the NASA Langley Research Center (LaRC). Briefly, the performance of the HSRL hinges on the separation of molecular returns from particulate returns. ${ }^{3,4}$ The implementation of a unique Michelson Interferometer is a very efficient way of separating the returns (i.e., via an interferometric spectral filter). The unique interferometer utilizes an air spacer in one arm and a solid glass spacer in the other arm. Challenges arise when using such an interferometer in conjunction with the HSRL aboard aircraft due in part to the variations in glass temperature. Therefore, an exacting determination of the refractive index of the glass proposed for the interferometer, Heraeus Homosil, was needed over a broad temperature range at the operational wavelength of $0.354 \mu \mathrm{m}$. This measurement pushed the CHARMS facility simultaneously to both a new short wavelength limit $(0.34 \mu \mathrm{m})$ and a new high temperature limit $(335 \mathrm{~K})$.

This paper reports the absolute index of refraction over the wavelength range $0.34-3.16 \mu \mathrm{m}$ and temperature range $\sim 120-335 \mathrm{~K}$ measured on Heraeus Homosil. The short wavelength limit of $0.34 \mu \mathrm{m}$ represents an extension of the previous capabilities of the CHARMS facility. The previous short wavelength limit of $0.40 \mu \mathrm{m}$ was primarily tied to the diminishing output of the Quartz Tungsten Halogen (QTH) source lamp that was used to feed the CHARMS monochromator. To extend the lower wavelength limit, the QTH lamp was replaced with the Energetiq EQ-99. The EQ-99 is a laser-driver plasma light source that exceeds the output of standard deuterium lamps in the 0.18 to $0.40 \mu \mathrm{m}$ range by roughly two orders of magnitude. The unique challenge of free space coupling the EQ-99 to the CHARMS monochromator was elongating the $\sim 100 \mu \mathrm{m}$ diameter image of the source to uniformly fill a $\sim 3 \mathrm{~cm} \times 80 \mu \mathrm{m}$ slit. We intentionally introduced astigmatism in the image to create a pseudo line source by glancing the diverting EQ-99 source off a spherical mirror. (Note, the f-number of the spherical mirror was matched to the f-number of the CHARMS monochromator.) The newly established short wavelength limit was defined by the efficiency of the grating monochromator installed and the selection of order-sorting filters utilized. A replacement grating and set of order- 
sorting filters that would allow coverage below $0.34 \mu \mathrm{m}$ and to the $5.0 \mu \mathrm{m}$ upper limit, without breaking configuration, are being investigated. The high temperature limit of $335 \mathrm{~K}$ was achieved by simply allowing the heater to slowly ramp. Glass from the specific Heraeus Homosil melt was polished into a prism geometry. CHARMS measurements are absolute - taken in high vacuum ( $<1 \mathrm{e}-5$ Torr), so that the index of the surrounding medium is unity.

\section{PRESENTATION OF MEASURED INDEX DATA}

CHARMS is a minimum deviation refractometer. Minimum deviation refractometry is the most accurate available method for obtaining the real part of the refractive index, $\mathrm{n}$. The condition of minimum deviation is met when light transits the prism perpendicular to the bisector of the prism's apex. Minimum deviation refractometry has an advantage over other techniques used to obtain refractive index (e.g., Kramers-Kronig transformation of broadband reflectance or transmittance) because it can be a few orders of magnitude more precise and accurate and does not depend on extrapolations. A detailed description of the data acquisition and data reduction processes of CHARMS is documented elsewhere. ${ }^{1}$ Raw index data as a function of temperature and wavelength are fit to a Sellmeier model of the following form:

$$
n^{2}(\lambda, T)=\sum_{j=1}^{3} \frac{S_{i}(T) \cdot \lambda^{2}}{\lambda^{2}-\lambda_{i}^{2}(T)}
$$

where the $S_{\mathrm{i}}$ terms represent the strengths of theoretical resonance features at center frequencies defined by their respectively indexed $\lambda_{\mathrm{i}}$ 's. It is generally found that the first three or four terms of the summation $(\mathrm{j}=3$ or 4$)$ are sufficient to generate adequate fits of smoothly varying index spectra over temperature and wavelength space. Typical Sellmeier fits generated agree with the raw measured index values to less than our measurement uncertainties (cf. Section 4). Extrapolation beyond the measured range is strongly discouraged as unpredictable results are likely, and disappointing performance in as-built lenses systems abound. The wavelength range of applicability for the Sellmeier coefficients reported here is $0.34-3.16 \mu \mathrm{m}$. The temperature range of applicability for each glass is listed in Table 1 .

\section{MEASUREMENT DETAILS AND FIT COEFFICIENTS}

Table 1 lists summarizing parameters from the CHARMS measurement of Heraeus Homosil presented herein. The stated apex angle holds significance out to five decimal places. This exacting determination of apex angle is provided by high accuracy absolute encoders and the ultra-high resolution, nulling, electronic autocollimator are used to determine the angle between adjacent refracting faces of the prism. The apex measurement is repeated at four separate orientations spaced by $90^{\circ}$ on a spindle platform to reduce systematic errors. The number of deviations represents the raw number of independent index measurements made over the stated wavelength and temperature range. The average absolute residual is obtained by taking the average of the absolute values of the differences between each measured index value (i.e., all 1531 values) and the corresponding index value computed by our Sellmeier fit at that respective wavelength and temperature. The average absolute residual supports how well our fit agrees with our raw measured data. Table 2 contains the temperature-dependent Sellmeier coefficients to third order. We observed that fourth order fits made a negligible (2E-8) improvement to the average absolute residual. All 24 coefficients of the third order Sellmeier equation were free parameters for optimization under the constraint that a positive overall value is generated on the right side of equation 1.

Table 1. Prism ID, apex angle, raw index measurements (\# of deviations), average absolute residual, and measured temperature range

\begin{tabular}{|c|c|c|c|c|c|}
\hline Prism ID & apex angle $\left[{ }^{\circ}\right]$ & \# of deviations & average absolute residual & temp. range $[\mathrm{K}]$ & wavelength range $[\mu \mathrm{m}]$ \\
\hline Homosil & 59.061271 & 1531 & $5.07 \mathrm{E}-06$ & $120-335 \mathrm{~K}$ & $0.34-3.16$ \\
\hline
\end{tabular}

Table 2. Third order temperature-dependent Sellmeier fit coefficients to the absolute refractive indices of Heraeus Homosil. 


\begin{tabular}{|c|c|c|c|c|c|c|}
\hline \multicolumn{7}{|c|}{$\begin{array}{l}\text { Coefficients for the temperature-dependent Sellmeier equation for Heraeus Homosil } \\
\qquad 120 \mathrm{~K} \leq \mathrm{T} \leq 335 \mathrm{~K} ; 0.34 \mu \mathrm{m} \leq \lambda \leq 3.16 \mu \mathrm{m}\end{array}$} \\
\hline & $\mathrm{S}_{1}$ & $\mathrm{~S}_{2}$ & $\mathrm{~S}_{3}$ & $\lambda_{1}$ & $\lambda_{2}$ & $\lambda_{3}$ \\
\hline Constant term & $1.29225 \mathrm{E}-01$ & 9.71572E-01 & $8.27751 \mathrm{E}-01$ & $2.51954 \mathrm{E}-02$ & $9.21570 \mathrm{E}-02$ & $9.60864 \mathrm{E}+00$ \\
\hline T term & $1.90245 \mathrm{E}-03$ & $-1.89331 \mathrm{E}-03$ & $1.40059 \mathrm{E}-03$ & $5.60903 \mathrm{E}-05$ & $1.29460 \mathrm{E}-04$ & $6.32992 \mathrm{E}-03$ \\
\hline$T^{2}$ term & $-2.20990 \mathrm{E}-06$ & $2.22447 \mathrm{E}-06$ & $-5.87619 \mathrm{E}-06$ & $5.25874 \mathrm{E}-07$ & $-3.74501 \mathrm{E}-07$ & $-2.63568 \mathrm{E}-05$ \\
\hline$T^{3}$ term & $-2.59028 \mathrm{E}-09$ & $2.61417 \mathrm{E}-09$ & $6.96388 \mathrm{E}-09$ & $-1.43461 \mathrm{E}-09$ & $3.50573 \mathrm{E}-10$ & $3.06661 \mathrm{E}-08$ \\
\hline
\end{tabular}

\section{MEASUREMENT UNCERTAINTIES}

The infrastructure employed within the CHARMS facility strives to achieve the highest achievable accuracy and precision over the available wavelength and temperature space by minimizing all sources of systematic error associated with the minimum deviation refractometry. A comprehensive CHARMS report detailing the most significant contributors to index errors has been previously published..$^{5}$ In what follows, a brief summary of the sources of error and ultimate extraction of measurement uncertainties is presented.

At the condition of minimum deviation, the index of refraction of a material is defined by the following expression:

$$
n=\frac{\sin \left(\frac{\alpha+\delta}{2}\right)}{\sin \left(\frac{\alpha}{2}\right)} \text {, }
$$

where $\delta$ is the deviation angle subtended by the refracting light and $\alpha$ is the angle between refracting faces. The angle between the unobstructed path of the light and the path of light that is refracted by the glass defines the deviation angle. This angle is recorded by the rotation of a flat mirror that is capable of sending both beams of light towards a common detector. The flat mirror is on an ultra-low runout rotation bearing with absolute rotary encoders having diametrically opposed read stations. Measurement of the apex angle, $\alpha$, is detailed above in Section 3. The apex angle measurement, which also employs absolute rotary encodes, produces $<0.3$ arcsecond accuracy. The accuracy to which $\delta$ and $\alpha$ are measured is levied by the performance of the absolute rotary encoders, which read out the bearing angle accurately to less than $0.00003^{\circ}$ with a peak noise less than $0.00001^{\circ}$. Uncertainty in wavelength and temperature are the other dominant sources of error. Furthermore, knowledge of temperature (wavelength) can be a non-negligible function of temperature (wavelength) itself. The extent to which both wavelength and temperature influence the uncertainty in a material's index depends on how index varies with each respective parameter. Therefore, when calculating uncertainty, it is important to examine how spectral dispersion $(\mathrm{dn} / \mathrm{d} \lambda)$ and the thermo-optic coefficient $(\mathrm{dn} / \mathrm{dT})$ each vary with wavelength and temperature. The $\mathrm{dn} / \mathrm{dT}$ and $\mathrm{dn} / \mathrm{d} \lambda$ are computed analytically from derivatives of the Sellmeier equation. Once all constituent uncertainties are determined, they are combined appropriately into the overall uncertainty for the measurement. The uncertainties of Heraeus Homosil at selected wavelengths and temperatures are reported in Table 3.

Table 3. Uncertainty in measured refractive index of Heraeus Homosil for representative wavelengths and temperatures.

\begin{tabular}{|c|c|c|c|c|c|}
\hline wavelength & $150 \mathrm{~K}$ & $200 \mathrm{~K}$ & $250 \mathrm{~K}$ & $300 \mathrm{~K}$ & $330 \mathrm{~K}$ \\
\hline $0.35 \mu \mathrm{m}$ & $3.55 \mathrm{E}-05$ & $3.21 \mathrm{E}-05$ & $2.90 \mathrm{E}-05$ & $2.12 \mathrm{E}-05$ & $1.95 \mathrm{E}-05$ \\
$0.5 \mu \mathrm{m}$ & $2.31 \mathrm{E}-05$ & $2.03 \mathrm{E}-05$ & $1.74 \mathrm{E}-05$ & $1.05 \mathrm{E}-05$ & $8.83 \mathrm{E}-06$ \\
$1.0 \mu \mathrm{m}$ & $1.97 \mathrm{E}-05$ & $1.69 \mathrm{E}-05$ & $1.40 \mathrm{E}-05$ & $7.63 \mathrm{E}-06$ & $6.04 \mathrm{E}-06$ \\
$2.0 \mu \mathrm{m}$ & $2.18 \mathrm{E}-05$ & $1.94 \mathrm{E}-05$ & $1.65 \mathrm{E}-05$ & $1.00 \mathrm{E}-05$ & $8.41 \mathrm{E}-06$ \\
$3.0 \mu \mathrm{m}$ & $2.20 \mathrm{E}-05$ & $1.99 \mathrm{E}-05$ & $1.69 \mathrm{E}-05$ & $1.04 \mathrm{E}-05$ & $8.69 \mathrm{E}-06$ \\
\hline
\end{tabular}




\section{REFRACTIVE INEX OF HERAEUS HOMOSIL}

The absolute refractive index of Heraeus Homosil at selected temperatures over the $0.34-3.16 \mu \mathrm{m}$ range is shown in Fig. 1. At the short wavelength end, the measurement was limited by the grating monochromator and selection of ordersorting filters installed in CHARMS. The index trends upward as it impinges on the absorption edge of the material at roughly $170 \mu \mathrm{m}$. At the long wavelength end the measurement was limited by the transmittance of the glass. The index was measured at multiple wavelengths longer than the strong $2.7 \mu \mathrm{m}$ absorption in Heraeus Homosil, ${ }^{6}$ an absorption associated with the $\mathrm{O}-\mathrm{H}$ vibration of water in the $\mathrm{SiO}_{2}$ structure. Figure 2 depicts the dispersion of index with wavelength over the measured range at the same selected temperatures. Upon close examination it can be determined that the dispersion increases in magnitude with increasing temperature below $1.3 \mu \mathrm{m}$ and has the opposite trend above $1.3 \mu \mathrm{m}$. The thermal-optic coefficient is presented in Fig. 3. The thermo-optic coefficient is positive over the entire measured range and it decreases with decreasing temperature. The tabulated values at selected wavelengths for the absolute index, dispersion, and thermo-optic coefficient are provides in Tables 4, 5, and 6, respectively.

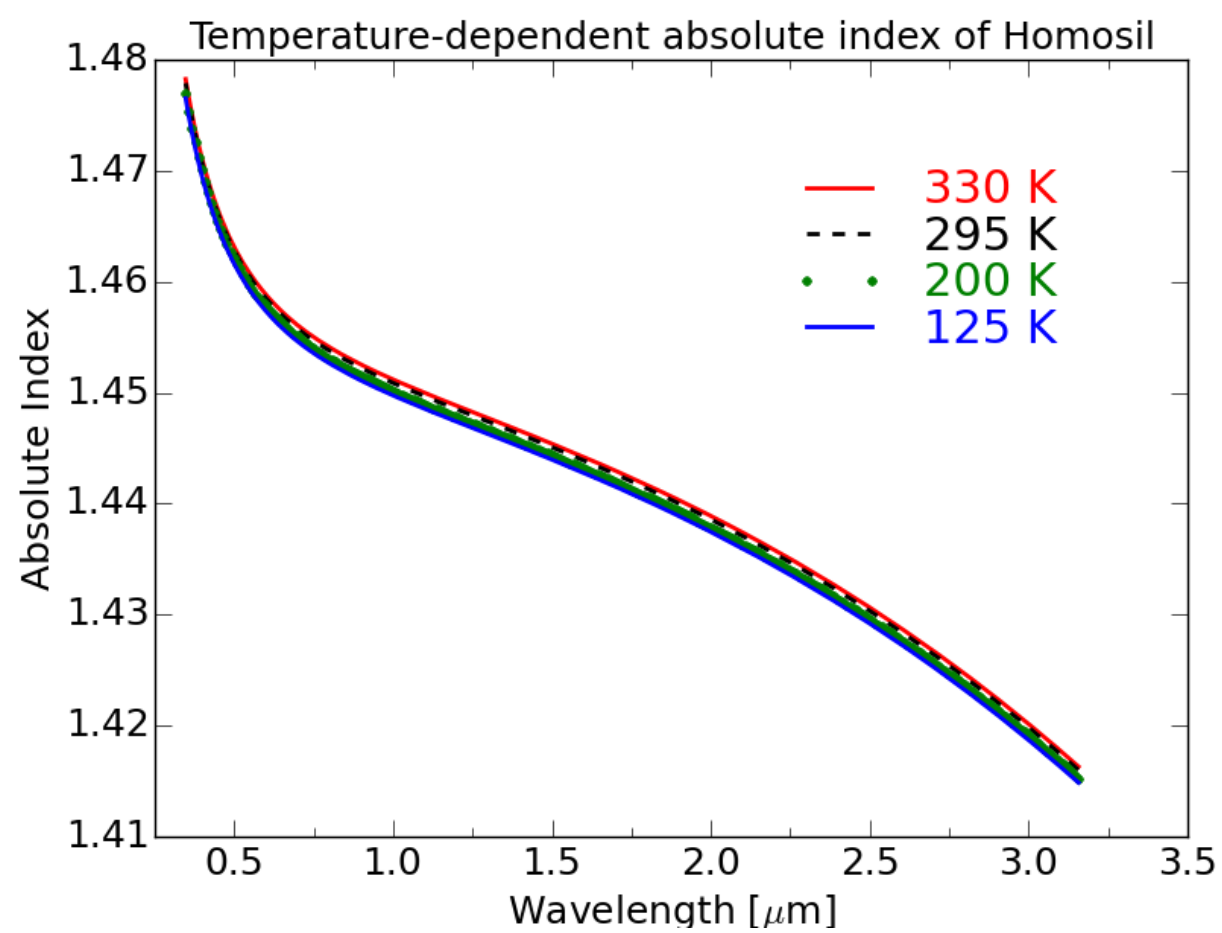

Figure 1: The absolute temperature-dependent refractive index of Heraeus Homosil over the wavelength range 0.34 to $3.16 \mu \mathrm{m}$. 


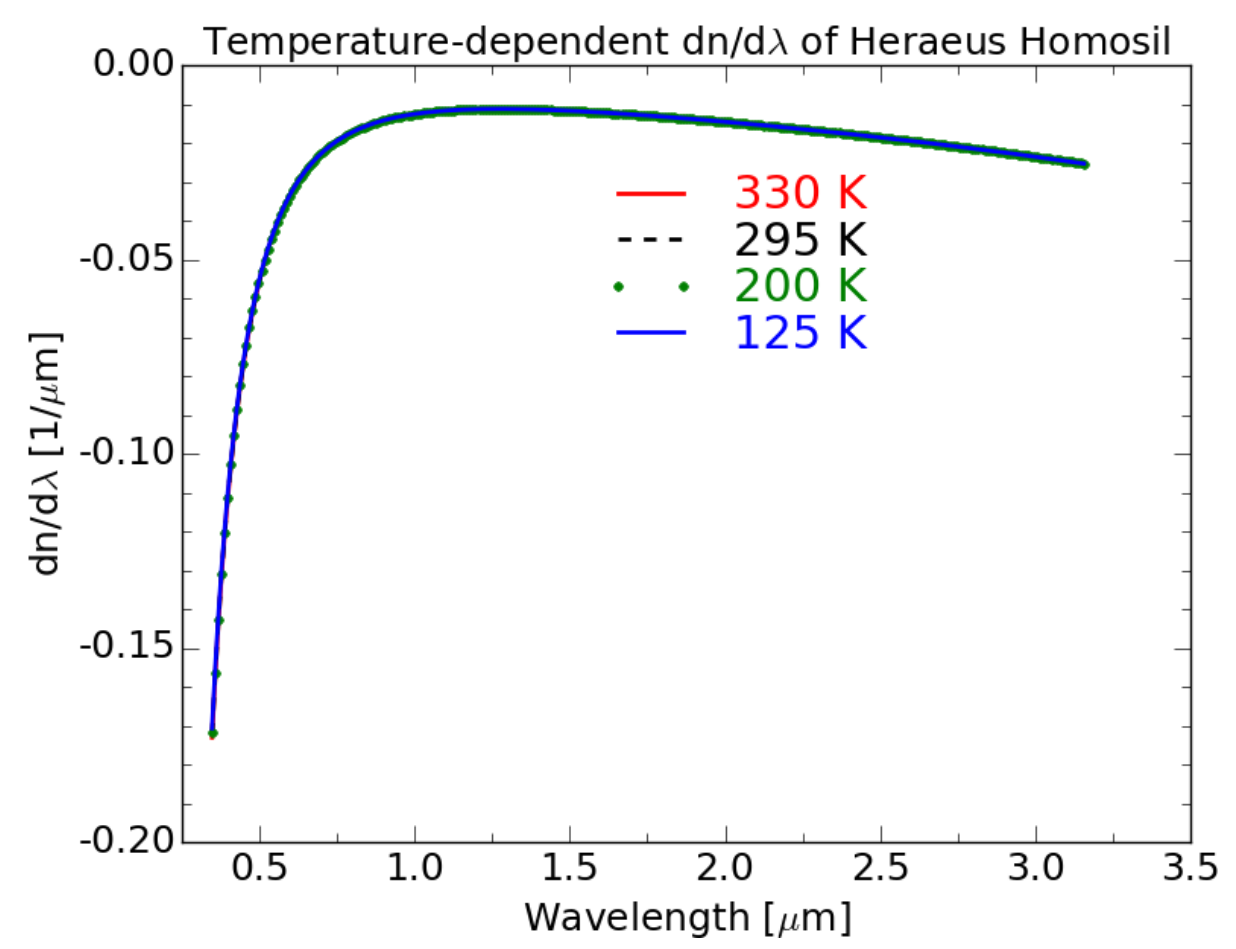

Figure 2: The dispersion of index with respect to wavelength of Heraeus Homosil over the wavelength range 0.34 to $3.16 \mu \mathrm{m}$ at discrete temperatures over the measured range.

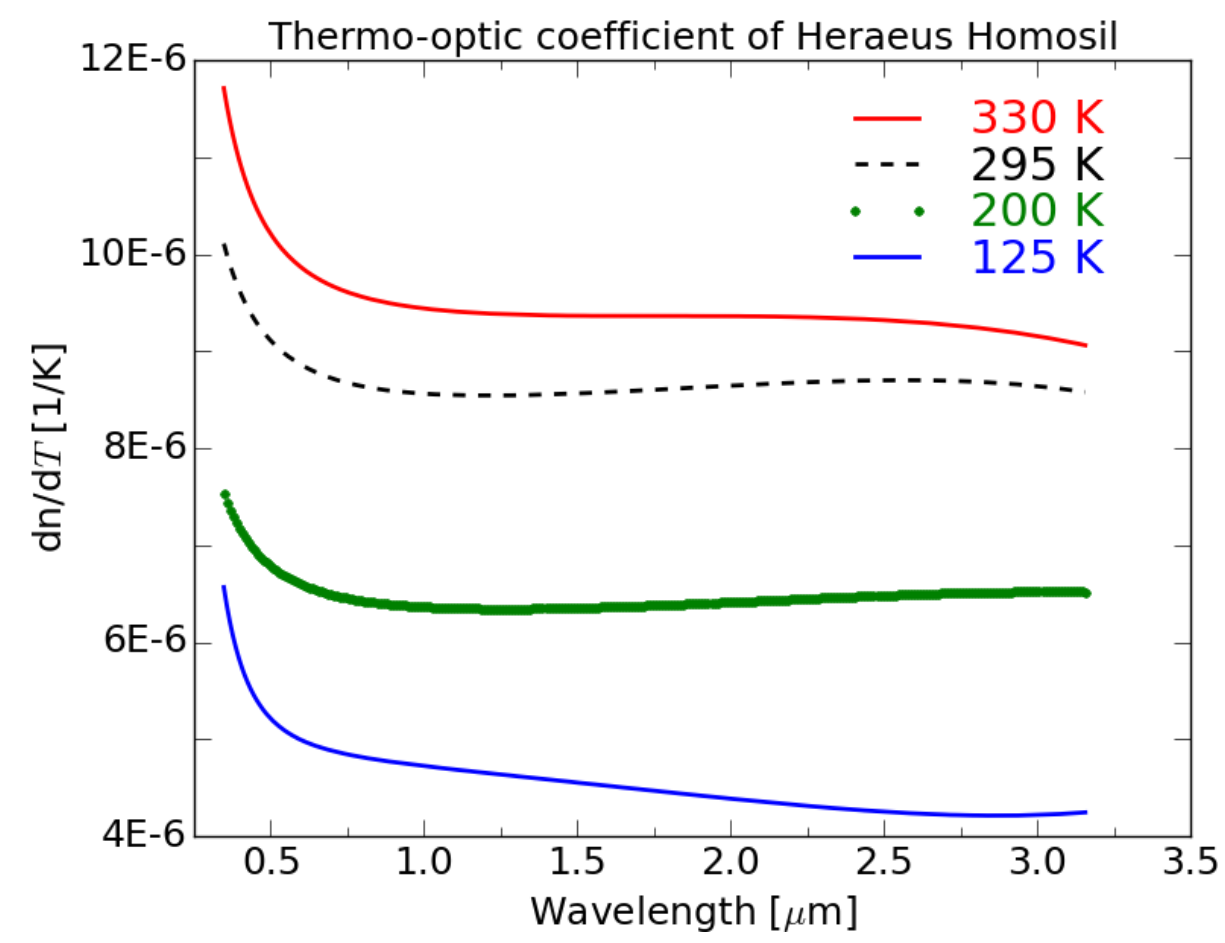

Figure 3: The thermo-optic coefficient of Heraeus Homosil over the wavelength range 0.34 to $0.31 \mu \mathrm{m}$ at discrete temperatures over the measured range. 
Table 4: The absolute refractive index, $\mathrm{n}$, of Heraeus Homosil at selected wavelengths and temperatures.

\begin{tabular}{|c|c|c|c|c|c|c|c|c|c|}
\hline wavelength & $125 \mathrm{~K}$ & $150 \mathrm{~K}$ & $175 \mathrm{~K}$ & $200 \mathrm{~K}$ & $225 \mathrm{~K}$ & $250 \mathrm{~K}$ & $275 \mathrm{~K}$ & $300 \mathrm{~K}$ & $325 \mathrm{~K}$ \\
\hline $0.4 \mu \mathrm{m}$ & 1.46932 & 1.46946 & 1.46961 & 1.46978 & 1.46996 & 1.47017 & 1.4704 & 1.47059 & 1.47089 \\
\hline $0.6 \mu \mathrm{m}$ & 1.45733 & 1.45746 & 1.4576 & 1.45775 & 1.45793 & 1.45812 & 1.45832 & 1.45849 & 1.45877 \\
\hline $0.8 \mu \mathrm{m}$ & 1.45263 & 1.45276 & 1.4529 & 1.45305 & 1.45322 & 1.4534 & 1.4536 & 1.45377 & 1.45404 \\
\hline $1.0 \mu \mathrm{m}$ & 1.44975 & 1.44987 & 1.45001 & 1.45016 & 1.45033 & 1.45051 & 1.4507 & 1.45087 & 1.45114 \\
\hline $1.2 \mu \mathrm{m}$ & 1.44739 & 1.44751 & 1.44765 & 1.4478 & 1.44796 & 1.44814 & 1.44834 & 1.44851 & 1.44877 \\
\hline $1.4 \mu \mathrm{m}$ & 1.44512 & 1.44524 & 1.44538 & 1.44553 & 1.4457 & 1.44588 & 1.44607 & 1.44624 & 1.44651 \\
\hline $1.6 \mu \mathrm{m}$ & 1.44277 & 1.44289 & 1.44302 & 1.44317 & 1.44334 & 1.44352 & 1.44372 & 1.44389 & 1.44415 \\
\hline $1.8 \mu \mathrm{m}$ & 1.44023 & 1.44035 & 1.44048 & 1.44063 & 1.4408 & 1.44098 & 1.44118 & 1.44135 & 1.44162 \\
\hline $2.0 \mu \mathrm{m}$ & 1.43745 & 1.43757 & 1.4377 & 1.43785 & 1.43802 & 1.43821 & 1.4384 & 1.43857 & 1.43884 \\
\hline $2.2 \mu \mathrm{m}$ & 1.43439 & 1.4345 & 1.43464 & 1.43479 & 1.43496 & 1.43514 & 1.43534 & 1.43551 & 1.43578 \\
\hline $2.4 \mu \mathrm{m}$ & 1.43101 & 1.43113 & 1.43126 & 1.43141 & 1.43158 & 1.43177 & 1.43197 & 1.43214 & 1.43241 \\
\hline $2.6 \mu \mathrm{m}$ & 1.42729 & 1.42741 & 1.42754 & 1.42769 & 1.42786 & 1.42805 & 1.42825 & 1.42842 & 1.42869 \\
\hline $2.8 \mu \mathrm{m}$ & 1.42319 & 1.42331 & 1.42345 & 1.4236 & 1.42377 & 1.42396 & 1.42416 & 1.42433 & 1.4246 \\
\hline $3.0 \mu \mathrm{m}$ & 1.41869 & 1.41881 & 1.41895 & 1.4191 & 1.41927 & 1.41946 & 1.41966 & 1.41983 & 1.42009 \\
\hline
\end{tabular}

Table 5: The spectral dispersion, $\mathrm{dn} / \mathrm{d} \lambda$, of Heraeus Homosil at selected wavelengths and temperatures in units of $1 / \mu \mathrm{m}$.

\begin{tabular}{|c|c|c|c|c|c|c|c|c|c|}
\hline wavelength & $125 \mathrm{~K}$ & $150 \mathrm{~K}$ & $175 \mathrm{~K}$ & $200 \mathrm{~K}$ & $225 \mathrm{~K}$ & $250 \mathrm{~K}$ & $275 \mathrm{~K}$ & $300 \mathrm{~K}$ & $325 \mathrm{~K}$ \\
\hline $0.4 \mu \mathrm{m}$ & -0.10817 & -0.10835 & -0.10847 & -0.10859 & -0.10874 & -0.10891 & -0.10909 & -0.10924 & -0.10949 \\
\hline $0.6 \mu \mathrm{m}$ & -0.0331 & -0.03313 & -0.03315 & -0.03317 & -0.03321 & -0.03326 & -0.03331 & -0.03335 & -0.03341 \\
$0.8 \mu \mathrm{m}$ & -0.0172 & -0.01721 & -0.01722 & -0.01723 & -0.01724 & -0.01726 & -0.01728 & -0.01729 & -0.01731 \\
$1.0 \mu \mathrm{m}$ & -0.01258 & -0.01258 & -0.01259 & -0.01259 & -0.01259 & -0.0126 & -0.01261 & -0.01261 & -0.01262 \\
$1.2 \mu \mathrm{m}$ & -0.01135 & -0.01135 & -0.01135 & -0.01135 & -0.01136 & -0.01136 & -0.01136 & -0.01136 & -0.01136 \\
\hline $1.4 \mu \mathrm{m}$ & -0.01145 & -0.01145 & -0.01145 & -0.01145 & -0.01145 & -0.01145 & -0.01145 & -0.01144 & -0.01144 \\
\hline $1.6 \mu \mathrm{m}$ & -0.01218 & -0.01218 & -0.01218 & -0.01218 & -0.01218 & -0.01217 & -0.01217 & -0.01217 & -0.01216 \\
\hline $1.8 \mu \mathrm{m}$ & -0.01326 & -0.01327 & -0.01327 & -0.01326 & -0.01326 & -0.01326 & -0.01325 & -0.01325 & -0.01324 \\
\hline $2.0 \mu \mathrm{m}$ & -0.01458 & -0.01458 & -0.01458 & -0.01458 & -0.01458 & -0.01457 & -0.01456 & -0.01456 & -0.01456 \\
\hline $2.2 \mu \mathrm{m}$ & -0.01607 & -0.01607 & -0.01607 & -0.01607 & -0.01607 & -0.01606 & -0.01606 & -0.01605 & -0.01605 \\
\hline $2.4 \mu \mathrm{m}$ & -0.01772 & -0.01772 & -0.01772 & -0.01772 & -0.01771 & -0.01771 & -0.0177 & -0.0177 & -0.0177 \\
\hline $2.6 \mu \mathrm{m}$ & -0.01951 & -0.01951 & -0.01951 & -0.01951 & -0.01951 & -0.0195 & -0.0195 & -0.0195 & -0.0195 \\
\hline $2.8 \mu \mathrm{m}$ & -0.02146 & -0.02146 & -0.02146 & -0.02146 & -0.02145 & -0.02145 & -0.02145 & -0.02146 & -0.02146 \\
\hline $3.0 \mu \mathrm{m}$ & -0.02357 & -0.02357 & -0.02356 & -0.02356 & -0.02356 & -0.02357 & -0.02357 & -0.02358 & -0.02359 \\
\hline
\end{tabular}

Table 6: The thermo-optic coefficient, dn/dT, of Heraeus Homosil at selected wavelengths and temperatures in units of 1/K.

\begin{tabular}{|c|c|c|c|c|c|c|c|c|c|c|}
\hline wavelength & $125 \mathrm{~K}$ & $150 \mathrm{~K}$ & $175 \mathrm{~K}$ & $200 \mathrm{~K}$ & $225 \mathrm{~K}$ & $250 \mathrm{~K}$ & $275 \mathrm{~K}$ & $300 \mathrm{~K}$ & $325 \mathrm{~K}$ \\
\hline $0.4 \mu \mathrm{m}$ & $5.79 \mathrm{E}-06$ & $5.74 \mathrm{E}-06$ & $6.3 \mathrm{E}-06$ & $7.15 \mathrm{E}-06$ & $8.01 \mathrm{E}-06$ & $8.7 \mathrm{E}-06$ & $9.21 \mathrm{E}-06$ & $9.73 \mathrm{E}-06$ & $1.07 \mathrm{E}-05$ \\
$0.6 \mu \mathrm{m}$ & $4.99 \mathrm{E}-06$ & $5.31 \mathrm{E}-06$ & $5.9 \mathrm{E}-06$ & $6.6 \mathrm{E}-06$ & $7.29 \mathrm{E}-06$ & $7.9 \mathrm{E}-06$ & $8.44 \mathrm{E}-06$ & $8.97 \mathrm{E}-06$ & $9.68 \mathrm{E}-06$ \\
$0.8 \mu \mathrm{m}$ & $4.81 \mathrm{E}-06$ & $5.23 \mathrm{E}-06$ & $5.8 \mathrm{E}-06$ & $6.43 \mathrm{E}-06$ & $7.06 \mathrm{E}-06$ & $7.65 \mathrm{E}-06$ & $8.2 \mathrm{E}-06$ & $8.75 \mathrm{E}-06$ & $9.4 \mathrm{E}-06$ \\
$1.0 \mu \mathrm{m}$ & $4.72 \mathrm{E}-06$ & $5.19 \mathrm{E}-06$ & $5.76 \mathrm{E}-06$ & $6.36 \mathrm{E}-06$ & $6.97 \mathrm{E}-06$ & $7.56 \mathrm{E}-06$ & $8.11 \mathrm{E}-06$ & $8.68 \mathrm{E}-06$ & $9.3 \mathrm{E}-06$ \\
$1.2 \mu \mathrm{m}$ & $4.65 \mathrm{E}-06$ & $5.17 \mathrm{E}-06$ & $5.74 \mathrm{E}-06$ & $6.35 \mathrm{E}-06$ & $6.95 \mathrm{E}-06$ & $7.53 \mathrm{E}-06$ & $8.09 \mathrm{E}-06$ & $8.66 \mathrm{E}-06$ & $9.26 \mathrm{E}-06$ \\
$1.4 \mu \mathrm{m}$ & $4.59 \mathrm{E}-06$ & $5.14 \mathrm{E}-06$ & $5.74 \mathrm{E}-06$ & $6.35 \mathrm{E}-06$ & $6.95 \mathrm{E}-06$ & $7.54 \mathrm{E}-06$ & $8.11 \mathrm{E}-06$ & $8.67 \mathrm{E}-06$ & $9.25 \mathrm{E}-06$ \\
\hline $1.6 \mu \mathrm{m}$ & $4.52 \mathrm{E}-06$ & $5.12 \mathrm{E}-06$ & $5.74 \mathrm{E}-06$ & $6.36 \mathrm{E}-06$ & $6.98 \mathrm{E}-06$ & $7.57 \mathrm{E}-06$ & $8.13 \mathrm{E}-06$ & $8.69 \mathrm{E}-06$ & $9.25 \mathrm{E}-06$ \\
\hline $1.8 \mu \mathrm{m}$ & $4.45 \mathrm{E}-06$ & $5.1 \mathrm{E}-06$ & $5.75 \mathrm{E}-06$ & $6.39 \mathrm{E}-06$ & $7.01 \mathrm{E}-06$ & $7.6 \mathrm{E}-06$ & $8.17 \mathrm{E}-06$ & $8.72 \mathrm{E}-06$ & $9.25 \mathrm{E}-06$ \\
$2.0 \mu \mathrm{m}$ & $4.39 \mathrm{E}-06$ & $5.08 \mathrm{E}-06$ & $5.76 \mathrm{E}-06$ & $6.41 \mathrm{E}-06$ & $7.05 \mathrm{E}-06$ & $7.65 \mathrm{E}-06$ & $8.21 \mathrm{E}-06$ & $8.75 \mathrm{E}-06$ & $9.26 \mathrm{E}-06$ \\
\hline $2.2 \mu \mathrm{m}$ & $4.33 \mathrm{E}-06$ & $5.06 \mathrm{E}-06$ & $5.77 \mathrm{E}-06$ & $6.44 \mathrm{E}-06$ & $7.08 \mathrm{E}-06$ & $7.69 \mathrm{E}-06$ & $8.25 \mathrm{E}-06$ & $8.77 \mathrm{E}-06$ & $9.26 \mathrm{E}-06$ \\
\hline $2.4 \mu \mathrm{m}$ & $4.27 \mathrm{E}-06$ & $5.05 \mathrm{E}-06$ & $5.78 \mathrm{E}-06$ & $6.47 \mathrm{E}-06$ & $7.12 \mathrm{E}-06$ & $7.73 \mathrm{E}-06$ & $8.28 \mathrm{E}-06$ & $8.79 \mathrm{E}-06$ & $9.25 \mathrm{E}-06$ \\
\hline $2.6 \mu \mathrm{m}$ & $4.23 \mathrm{E}-06$ & $5.04 \mathrm{E}-06$ & $5.79 \mathrm{E}-06$ & $6.49 \mathrm{E}-06$ & $7.15 \mathrm{E}-06$ & $7.75 \mathrm{E}-06$ & $8.3 \mathrm{E}-06$ & $8.79 \mathrm{E}-06$ & $9.22 \mathrm{E}-06$ \\
$2.8 \mu \mathrm{m}$ & $4.21 \mathrm{E}-06$ & $5.05 \mathrm{E}-06$ & $5.81 \mathrm{E}-06$ & $6.51 \mathrm{E}-06$ & $7.17 \mathrm{E}-06$ & $7.76 \mathrm{E}-06$ & $8.3 \mathrm{E}-06$ & $8.77 \mathrm{E}-06$ & $9.17 \mathrm{E}-06$ \\
$3.0 \mu \mathrm{m}$ & $4.22 \mathrm{E}-06$ & $5.06 \mathrm{E}-06$ & $5.82 \mathrm{E}-06$ & $6.52 \mathrm{E}-06$ & $7.17 \mathrm{E}-06$ & $7.75 \mathrm{E}-06$ & $8.27 \mathrm{E}-06$ & $8.72 \mathrm{E}-06$ & $9.09 \mathrm{E}-06$ \\
\hline
\end{tabular}




\section{DISCUSSION}

There is no refractive index data at cryogenic temperatures in the literature for Heraeus Homosil. However, the Heraeus glass catalog ${ }^{6}$ offers a densely populated table of refractive index for discrete wavelengths ranging from 0.2 to $3.4 \mu \mathrm{m}$. The catalogue quotes that measured values have an accuracy of $\pm 3.0 \mathrm{E}-5$, which is greater than our single measurement uncertainty at $300 \mathrm{~K}$ (cf. Table 3). In general, catalogue refractive index values statistically represent many melts of a given glass type over time. We are advantaged here by the fact that, in contrast to other optical glasses, fused silica shows a smaller difference in refractive index from melt to melt. (Note, a comparative study of fused silica glasses measured on CHARMS is presented below in this section.) We have also located four thermo-optic coefficient data points in the Heraeus catalog that overlap our measured range.

Heraeus Homosil catalog index values are quoted at ambient pressure and $20^{\circ} \mathrm{C}$. We must first scale the catalog values to their respective vacuum values in order to compare them to index measurements from CHARMS. This is accomplished by multiplying the values relative to air by the spectral refractive index of air, $\mathrm{n}_{\text {air }}(\lambda)$. For our comparison, we plot the difference between the scaled Heraeus Homosil indices and the indices from our CHARMS Sellmeier fit calculated at $293 \mathrm{~K}$ in the wavelength region where the two data sets overlap. (Note, the Heraeus catalog values span a wider wavelength range than the CHARMS values so a comprehensive comparison to our data set at $293 \mathrm{~K}$ is achieved.) The results of the comparison are shown in the left panel of Fig. 4. The index difference ranges from 1.2E-4 at the short wavelength end to $-1.3 \mathrm{E}-5$ at the long wavelength end. Notably, the index difference profile takes on the same dispersion as the refractive index itself, yielding the largest index difference at the extremes of the wavelength scale. The average absolute residual of the comparison is $6.42 \mathrm{E}-5$, which is foreshadowed by the high density of catalog index values between 0.5 and $1.0 \mu \mathrm{m}$ as shown in the plot. The right panel of Fig. 4 shows the thermo-optic coefficient $(\mathrm{dn} / \mathrm{dT})$ difference between the values found in the catalog and the CHARMS values presented in this study. The catalog thermo-optic coefficient values were scaled to vacuum values using the same method described above. The average absolute residual of the thermo-optic coefficient comparison is $1.6 \mathrm{E}-6$, which is well below our single measurement uncertainty. The agreement of the four data points are excellent. It is noted that the catalog thermo-optic coefficient values are greater than the CHARMS values. A systematic trend in the data is not noted.
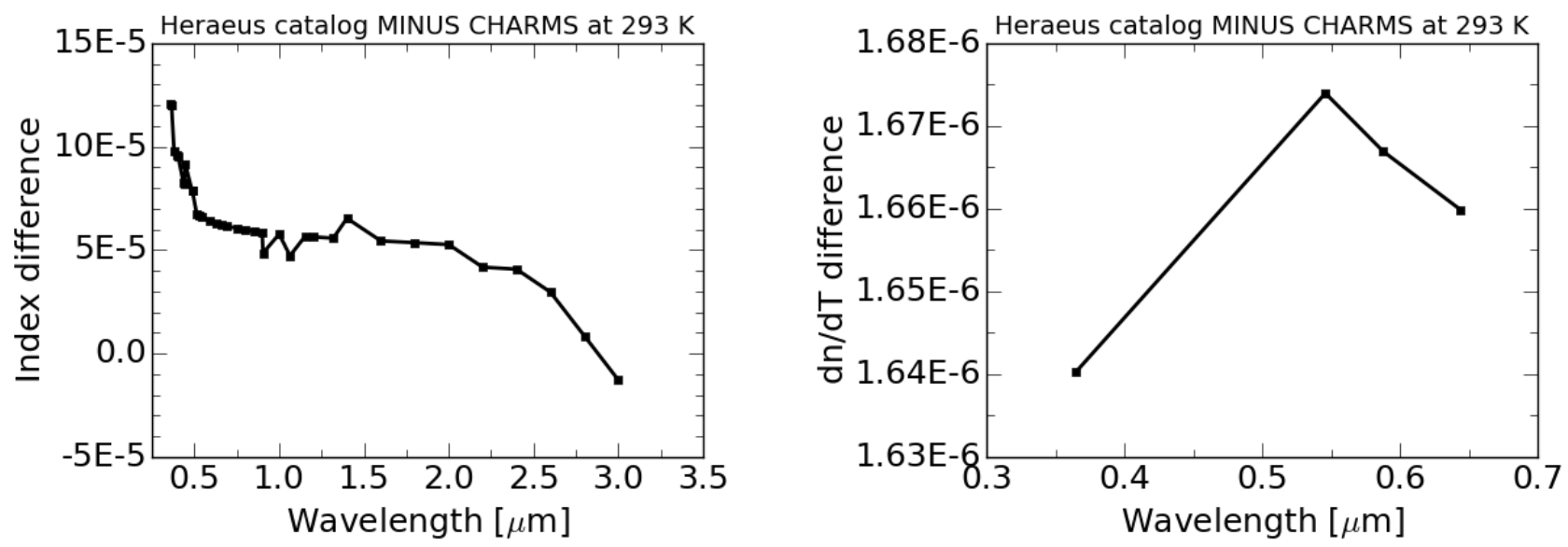

Figure 4. The difference between the Heraeus catalog indices (scaled to vacuum) and indices measured on CHARMS at $293 \mathrm{~K}$ (left panel), and the thermo-optic coefficient difference between the Heraeus catalog and CHARMS at $293 \mathrm{~K}$ (right panel).

We finally compare our $293 \mathrm{~K}$ absolute index data on Heraeus Homosil with past CHARMS literature of other fused silica-based glasses. The index difference between Heraeus Homosil and Infrasil $301,{ }^{7}$ also a Heraeus glass, represents the closest agreement. Infrasil 301 is systematically higher than Heraeus Homosil, and the index difference is nearly flat in the 5E-5 range. The Heraeus catalog applies the same set of index values for both Homosil and Infrasil 301, thus seemingly indicating that the difference between the two glasses (and from melt to melt) is below their measured accuracy range (3E-5). We have found that the difference between the specific Homosil melt presented here exceeds their measured accuracy range by 2E-5. The index difference between CHARMS measurements of Corning 7980 and 
Homosil represents a close second in the comparison ranking. ${ }^{8}$ Our measurements of Corning 7980 are systematically lower than the Homosil measurements, although the bulk of the difference values falls in the mid E-5 range. The index difference profile with Corning 7980 is systematically decreasing with increasing wavelength. Lastly, we compare Homosil with CHARMS measurements of Suprasil 3001, representing six different glasses from two distinct melts. ${ }^{9}$ The index difference with Homosil is again nearly flat and in the low 2E-4 range.

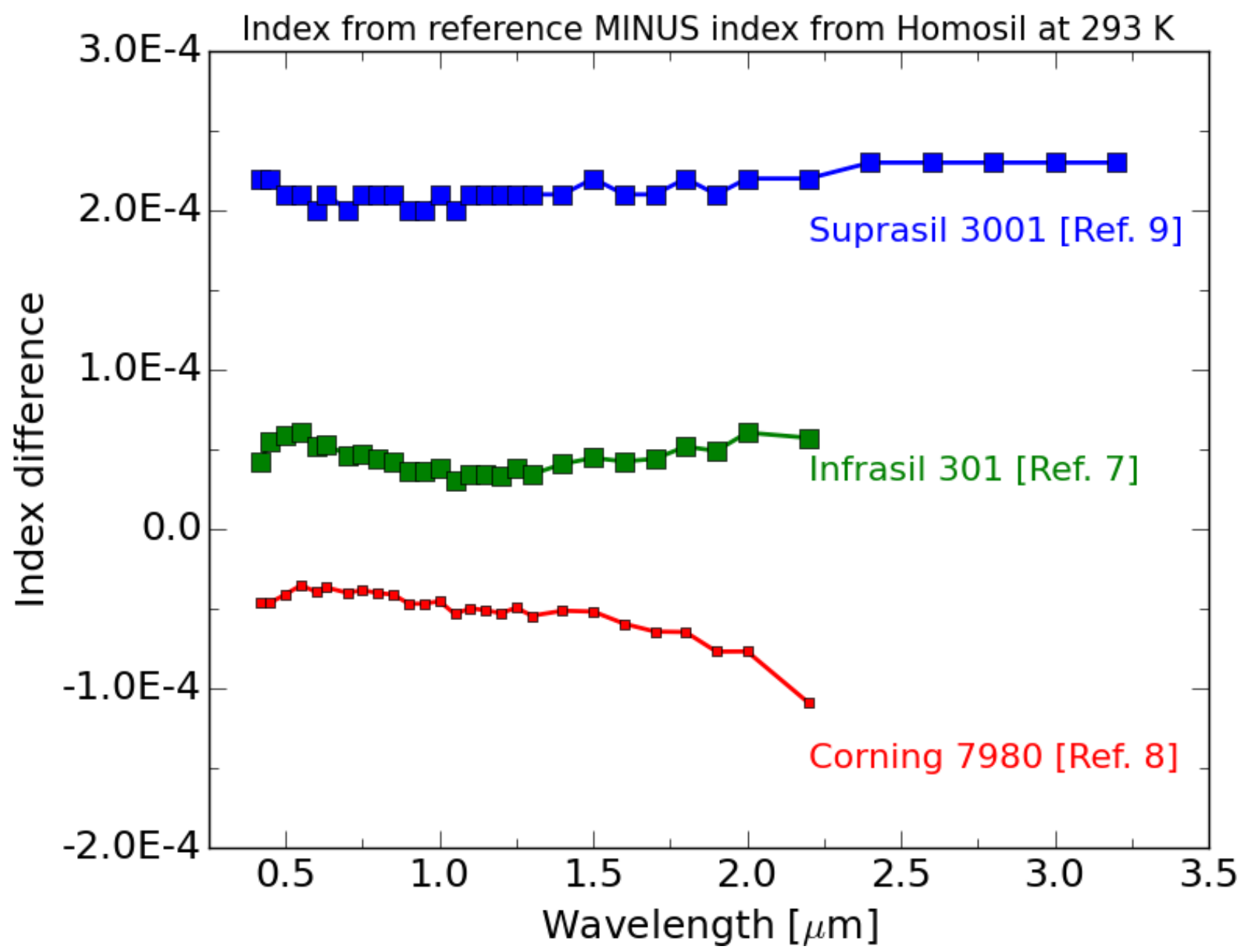

Figure 5. The index difference between CHARMS measurements on Heraeus Homosil and CHARMS measurements on other fused silica compounds at $293 \mathrm{~K}$.

\section{CONCLUSION}

We have measured the absolute refractive index of Heraeus Homosil over the wavelength range $0.34-3.16 \mu \mathrm{m}$ and temperature range $\sim 120-335 \mathrm{~K}$. We have fitted our temperature-dependent refractive index data set with a third order Sellmeier model. The average absolute residual of our modeled data (5.07E-6) agrees with the raw index data to within our calculated uncertainties (cf. Table 3) over the entire measured range. The average absolute residual is on the same order of magnitude as other exacting CHARMS measurements published in the literature. We have derived the spectral dispersion and thermo-optic coefficient for Heraeus Homosil based on dense temperature-wavelength coverage.

CHARMS index values of Heraeus Homosil were compared to the index values listed in the Heraeus catalog at ambient temperature and pressure. We observe an average difference of 6.42E-5 between CHARMS and the Heraeus catalog. Heraeus Homosil was compared with other fused silica-based glasses measured by CHARMS. Not surprisingly, our measurements of (Heraeus) Infrasil 301 resulted in the closest comparison, which was foreshadowed by the fact that the two glasses often share the same properties in the Heraeus catalog. 


\section{REFERENCES}

[1] Leviton, D. B., Frey, B.J., "Design of a cryogenic, high accuracy, absolute prism refractometer for infrared through far ultraviolet optical material," SPIE 4842, 259 (2003), http://dx.doi.org/10.1117/12.459479

[2] Frey, B. J., Leviton, D. B., Henry, R. M., Quijada, M. A., "Cryogenic high-accuracy absolute prism refractometer for infrared through far-ultra-violet optical materials: implementation and initial results," SPIE 5172, 119 (2003),

http://dx.doi.org/10.1117/12.506097

[3] Seaman, S.T., Cook, A.L., Scola, S.J., Hostetler, C.A., Miller, I., and Welch, W., "Performance characterization of a pressuretuned wide-angle Michelson interferometer spectral filter for high spectral resolution lidar," SPIE 9612, 1-7 (2015),

http://dx.doi.org/10.1117/12.2189114

[4] Scola, S.J., et al., "Structural-Thermal-Optical-Performance (STOP) Model Development and Analysis of a Field-widened Michelson Interferometer," SPIE 9193, 1-15 (2014), http://dx.doi.org/10.1117/12.2061041

[5] Leviton, D. B., Frey, B. J., Henry, R. M., "Temperature-dependent refractive index measurements of S-FPL51, S-FTM16, and STIM28 to cryogenic temperatures," SPIE 8863, (2013), http://dx.doi.org/10.1117/12.2024821

[6] Quartz Glass for Optics Data and Properties, Heraeus, December 2016, http://www.optics.heraeus0quarzglas.com

[7] Leviton, D. B., Frey, B. J., Madison, T., "Temperature-dependent refractive index of CaF2 and Infrasil 301," SPIE 6692, 1-11 (2007), http://dx.doi.org/10.1117/12.735594

[8] Leviton, D. B., Frey, B.J., “Temperature-dependent absolute refractive index measurement of synthetic fused silica," SPIE 6273, 1-11 (2006), http://dx.doi.org/10.1117/12.672853

[9] Leviton, D. B., Miller, K.H., Quijada, M.A., "Temperature-dependent refractive index measurements of CaF2, Suprasil3001, and S-FTM16 for the Euclid near-infrared spectrometer and photometer," SPIE 9578, 1-12 (2015), http://dx.doi.org/10.1117/12.2189024 